\title{
Sobre a Semiótica das Paixões
}

\author{
Luiz Carlos Migliozzi Ferreira de MELLO \\ Universidade Estadual de Londrina - UEL
}

Resumo: Com o aprofundamento nos estudos sobre a sintaxe narrativa e com a segurança que ela proporciona ao analista do discurso, a Semiótica aceita o desafio de investigar e de descrever as emoções humanas. O objetivo deste trabalho é discutir, dentre outras coisas, o conceito de paixão e os procedimentos a partir dos quais se torna possível explicar o surgimento do efeito passional. A paixão surge como o resultado do jogo entre as modalidades do querer ser, do dever ser, do saber ser e do poder ser. Cada uma destas modalidades pode desdobrar-se em quatro posições modais, já que se pode negar cada um dos predicados ou os dois ao mesmo tempo. A partir da modalidade do querer ser, por exemplo, pode-se chegar ao querer ser, ao não querer ser, ao querer não ser e ao não querer não ser. Uma paixão é, então, o fruto de arranjos modais. No entanto, o analista das paixões não pode limitar suas investigações aos arranjos modais, uma vez que uma mesma seqüência modal serve para explicar diferentes efeitos passionais. Para chegar a uma descrição passional ajuizada, faz-se necessária uma investigação mais ampla do discurso. É preciso incorporar ao exame dos arranjos modais uma análise das relações actanciais do discurso, dos programas e dos percursos narrativos.

Palavras-chave: Efeito Passional; Arranjo Modal; Relação Actancial; Programa Narrativo; Percurso Narrativo.

Abstract: With the profundity in the studies about narrative syntax and the safety it provides the discourse analyst, the Semiotics accepts the challenge to investigate and describe human emotion. The objective of this work is to discuss, among other things, the concept of passion and the procedures which make it possible to explain the arising of the passional effect. Passion appears as a result from the contest between the modalities of the wanting to be, having to be, knowing to be and being able to be. Each of these modalities can unfold into four modal positions, as it is possible to deny each one of the predicates or both at the same 
time. From the modality of the wanting to be, for example, it is possible to get to the wanting to be, the not wanting to be, the wanting not to be and the not wanting not to be. A passion is, therefore, the result of modal arrangements. However, the passion analyst cannot restrict his investigations to the modal arrangements, as the same modal sequence can be used to explain different passional effects. To reach a sensible passional description, a comprehensive investigation of the discourse is necessary. It is important to incorporate to the assessment of the modal arrangements an analysis of the actancial relations of the discourse, the narrative programming and the narrative trajectory.

Key words: Passional Effect; Modal Arrangement; Actancial Relation; Narrative Programming; Narrative Trajectory.

Resumen: Con el profundo estudio a respecto de la sintaxe narrativa y con la seguridad que ella le proporciona al analista del discurso, la semiótica acepta el desafío de averiguar y de describir las emociones humanas. El objetivo de este trabajo es discutir, entre otros temas, el concepto de pasión y los procedimientos desde los cuales se torna posible explicar el aparecimiento del efecto pasional. La pasión surge como el resultado del juego entre las modalidades del querer ser, del deber ser, del saber ser y del poder ser. Cada una de estas modalidades puede desmenbrarse en cuatro opciones modales, ya que se puede negar cada uno de los predicados o los dos al mismo tiempo. Por comenzar de la modalidad del querer ser, por ejemplo, se puede llegar al querer ser, al no querer ser, al querer no ser y al no querer no ser. Una pasión es, entonces, el fruto de arreglos modales. Sin embargo, el analista de las pasiones no puede limitar sus averiguaciones a los arreglos modales, una vez que una misma secuencia modal serviría para explicar diferentes efectos pasionales. Para llegar a una descripción pasional juiciosa, se hace necesaria una averiguación más amplia del discurso. Es necesario incorporar al examen de los arreglos modales una verificación de las relaciones actanciales del discurso, de los programas y de los percorridos narrativos.

Palabras-clave: Efecto Pasional; Arreglo Modal; Relación Actancial; Programa Narrativo; Percorrido Narrativo. 
A Semiótica, durante muito tempo, deixou de lado os estudos sobre as emoções humanas, temendo cair no subjetivismo da análise. Porém, com o aprofundamento nos estudos sobre a modalização do ser, o caminho tornou-se mais seguro. Ao estudar os valores investidos pelos sujeitos no objeto, foi possível detectar certos estados de alma desses sujeitos. É nesse momento que a Semiótica dedica-se ao estudo das paixões.

Paixões são "estados de alma" e a literatura sobre o assunto mostra que um "estado de coisas" leva a um "estado de alma". Assim, se a Semiótica estuda a busca do sujeito por objetos-valores, pode-se dizer que os "estados de alma" aparecem porque esses sujeitos, tentando entrar em conjunção com seus objetos-valores, criam "conflitos", "polêmicas" entre si ou, então, estabelecem entre si "situações de cumplicidade", "de benevolência". As paixões podem ser definidas como modalizações do ser dos sujeitos de estados narrativos, que, no nível discursivo, aparecem concretizadas por lexemas.

A propósito disso, Greimas e Courtés (1986, p. 162) explicam que as paixões podem ser compreendidas como o resultado de uma seqüência de "estados de alma". A paixão nasce com a modalização do ser e do fazer:

Par opposition à action, la passion peut être considerée comme une organisation syntagmatique d'états d'âme', en entendant par là l'habillage discursif de l'être modalisé des sujets narratifs. Les passions et les 'états d'âme' qui les composent sont le fait d'un acteur et contribuent, avec ses actions, à en déterminer des rôles dont il est le support. Cette opposition représente donc la conversion sur le plan discursif de l'opposition plus profonde et abstraite entre être et faire, ou, plus précisement, entre être modalisé et faire modalisé.

Em um outro momento das suas explicações sobre o termo paixão, Greimas e Courtés (1986, p. 163) explicam que a análise das paixões deve ser feita no nível narrativo:

La passion désigne un ensemble d'effets de sens qui surgissent trés fréquemment dans le champ narratif, mais qui n'ont pas trouvé leur analyse en termes de narratologie des actions. La 
passion s'exprime souvent à travers la figurativité sous-tendant la narrativité en question, mais elle est toujours liée à un sujet en principe déjà présenté comme actionnel - il semble que l'on ne puisse pâtir qu'après avoir agi, ou en agissant -, et doit donc être analysée au niveau strictement narratif.

Em "Le tumulte modal: de la macro-syntaxe à la microsyntaxe passionnalle", Fontanille defende a idéia de que "as paixões não têm origem a partir de modalidades isoladas, nem mesmo de feixes de modalidades, mas a partir de uma sintaxe intermodal" (1986, p. 12). Ele mesmo diz que a idéia não é original, mas deve ser abordada, não como mero efeito da descrição, e sim como idéia central do efeito passional:

Les passions ne s'engendrent pas à partir de modalités isolées, ni même de faisceaux de modalités, mais à partir d'une syntaxe inter-modale. Cette idée d'une syntaxe inter-modale n'a en ellemême rien d'original; elle est présente, explicitement ou implicitement, chez tous ceux qui ont tant soit peu étudié les passions (Fontanille, 1980; Greimas, 1981; Marsciani, 1984; Parret, 1986); mais elle n'est exploitée que comme un moment de la description, voire comme une méthode d'approche, et non comme le coeur même de l'effect passionnel.

Ao tratar dos arranjos modais ("agencements modaux"), Fontanille explica que Greimas, ao fazer das paixões a emanação temática e figurativa das modalizações do ser, distingue quatro modalidades diferentes: o querer ser, o dever ser, o saber ser e o poder ser. Cada uma destas modalidades é suscetível de se desdobrar em quatro posições modais, uma vez que se pode negar cada um dos predicados ou os dois ao mesmo tempo (ex. querer ser, não querer ser, querer não ser $\mathrm{e}$ não querer não ser). A dificuldade, explica Fontanille (1986, p. 12-13), vem do fato de que uma paixão é raramente o efeito de uma só modalização e esclarece:

La strate passionnelle à laquele Greimas parvient à donner une forme de cette manière est, selon nous, celle des 'modalisations thymisées', comme le laisse entendre d'ailleurs la présentation qu'il en fait. En revanche, dès qu'on cherche à construire des 
passions, pouvant se déployer en rôles pathémiques, il faut envisager un agencement modal complexe.

Sendo assim, Barros (1995, p. 91) salienta que os estudos das paixões podem ser separados em dois momentos distintos. No primeiro, as paixões são entendidas como "efeitos de sentido passionais produzidos no discurso como emanados da organização narrativa das estruturas modais, isto é, de um certo arranjo de modalidades do ser". E, em conseqüência, dessa concepção, os estudos das paixões ficaram estritamente vinculados à organização da narrativa e aos arranjos modais.

Ainda dentro dessa primeira etapa dos estudos das paixões, os efeitos de sentido dos arranjos modais modificariam o sujeito de estado, produzindo os efeitos passionais. A propósito disso, Barros (1995, p. 92) lembra:

A descrição das paixões se fez, nessa etapa, quase exclusivamente, em termos de sintaxe modal, ou seja, de relações modais e de suas combinações sintagmáticas. Assim [...] a organização sintagmática de modalidades - querer-ser, não crer-ser e saber não poder-ser - produz o efeito de sentido ‘afetivo’ de amargura.

Fica claro, então, que uma investigação sobre paixões não deve restringir-se apenas às investigações dos arranjos modais, embora essa atitude seja indispensável. Um estudo sobre paixão que se restringe à análise dos arranjos modais não consegue explicar o fato de uma mesma seqüência modal poder produzir diferentes efeitos passionais. Por exemplo, um não querer ser, associado a um não poder não ser, pode levar o sujeito ao desespero, à angústia, ao medo, à vergonha. Torna-se claro, assim, que o estudo sobre as paixões deve ir além dos arranjos modais.

E ir além dos arranjos modais significa analisar não fragmentos do discurso (sobretudo daquelas partes relacionadas ao sujeito de estado), mas ao discurso como um todo. E, para isso, faz-se necessária uma investigação sobre as relações actanciais do discurso, dos programas e dos percursos narrativos e não apenas dos arranjos de modalidades que, de forma mais direta, constituem a existência dos sujeitos. Barros (1995, p. 92) sintetiza essa visão da seguinte maneira: 
Para explicar as paixões, é necessário, portanto, recorrer às relações actanciais, aos programas e percursos narrativos. Só assim se podem determinar o sujeito que quer ser, o objeto de seu desejo, o sujeito em que o outro crê, o destinador a quem o sujeito passional quer fazer mal ou bem e assim por diante. A 'complexidade' das paixões depende em grande parte das estruturas narrativas. Em outras palavras, as paixões não são propriedade exclusiva dos sujeitos, mas dos discursos inteiros.

Várias foram as contribuições teóricas alcançadas pela Semiótica a partir dessa nova maneira de investigar as paixões. Barros (1995, p. 93) menciona três tendências que surgiram a partir das investigações das paixões no projeto da Semiótica. Primeiro, corroborou a necessidade de incluir as paixões no estudo da organização narrativa e na configuração do sujeito de estado. Segundo, enfatizou a importância da configuração do sujeito de estado em uma investigação semiótica. E, em terceiro lugar, obrigou a Semiótica a (re)definir as premissas teóricas sobre os "estados de alma" e sobre os efeitos de paixão.

A Semiótica distingue dois tipos de paixões, as simples e as complexas. As paixões simples são derivadas do arranjo modal oriundo da relação entre sujeito e objeto. Já as paixões complexas são aquelas derivadas de toda uma organização narrativa patêmica anterior. A propósito das paixões complexas, Barros (1990, p. 61) observa:

As modalidades se organizam em uma configuração patêmica e desenvolvem percursos. Os percursos modais sofrerão a variação tensiva própria da organização narrativa e caminharão da tensão 'passional' a seu relaxamento e vice-versa.

Dessa forma, lembra a autora (1995, p. 93), em um outro momento, que as paixões complexas pressupõem a existência de todo um percurso modal e de uma sucessão de estados de alma. Como exemplo, cita o rancor que faz pressupor a presença de um estado de espera e de confiança, um estado de decepscão, um estado de falta ou de insegurança e aflição, um estado de malevolência e, no fim, culminando com o rancor.

Barros (1995) apresenta algumas lexicalizações possíveis (paixão simples) decorrentes da modalização pelo querer ser. Segunda a autora, o querer ser faz aparecer o desejo, o anseio, a ambição, cobiça, a 
cupidez, a avidez e a curiosidade. Já o não querer não ser gera a avareza, a mesquinhez, a usura, a sovinice. O querer não ser torna-se responsável pelo aparecimento do desprendimento, da generosidade, da liberalidade, da prodigalidade. E, por fim, o não querer ser faz nascer a repulsa, o medo, a aversão, o desinteresse.

Ainda em relação às paixões simples, Barros (1990) aponta vários critérios para a diferenciação das várias paixões. O gran de intensidade do querer é um desses critérios. A autora explica que o desejo pode ser ardente, sôfrego, veemente, excessivo, violento, irreprimível, etc. Um outro critério apontado por ela diz respeito aos tipos de valores desejados. A respeito disso, escreve (1990, p. 61) que esses valores podem ser:

pragmático-descritivo na cobiça, na cupidez, na avareza, em que se desejam bens materiais; descritivo e modal, na ambição, em que se querer tanto ter quanto poder; indiferentemente pragmático ou modal, na inveja ou no anseio; cognitivo na curiosidade, que se define pelo querer-saber.

A autora apresenta, ainda, outros critérios para a classificação e diferenciação das paixões simples, como, por exemplo, a explicitação do desdobramento polêmico, a intenção de conservar o estado de conjunção ou, ainda, a intenção de transformar a disjunção em conjunção.

Quanto às paixões complexas, Barros (1990) lembra que elas são descritas a partir do estado inicial de espera. O sujeito da espera caracteriza-se pelas modalidades do querer ser e do crer ser. O sujeito da espera quer entrar (querer ser) em conjunção ou em disjunção com um objeto-valor, mas não fará nada para transformar seu estado inicial, já que espera/ acredita (crer ser) que um outro sujeito fará essa transformação de estado que ele deseja. Dessa forma, o sujeito da espera mantém uma relação de confiança em relação a um outro sujeito (sujeito do fazer) para transformar sua relação com o objeto-valor desejado. Como explicam Greimas e Fontanille (1993, p. 59), "o sujeito tensivo desdobrase em um 'outro' e interioriza o corpo outro como 'intersujeito' com base da fidúcia". Por isso mesmo, o sujeito da espera nada fará para entrar em conjunção ou em disjunção com o seu valor - do contrário, ter-se-ia uma paixão simples e não complexa. 
Estabelece-se, assim, um contrato entre o sujeito da espera e o sujeito do fazer. Acontece que, muitas vezes, esse contrato é apenas fruto da imaginação do sujeito da espera: tem-se, então, um contrato imaginário ou um pseudocontrato, como denominou Greimas. Barros (1995) lembra, ainda, que Greimas chamou o fazer cognitivo contratual do sujeito de construção de simulacros. É preciso, no entanto, que se esclareça que, apesar da unilateralidade da construção de um simulacro, ele determina as relações intersubjetivas. Assim, se o sujeito da espera $c r \hat{e}$ que o sujeito do fazer vai transformar seu estado de junção com o objeto-valor, o sujeito do fazer passa a dever fazer. Estabelece-se, assim, o contrato fiduciário.

Um outro ponto a salientar na construção do simulacro é que o sujeito do crer e o sujeito do ser não são, necessariamente, os mesmos sujeitos. Pode-se acreditar nas habilidades do outro em conseguir entrar em junção com o objeto-valor ou pode-se pensar nas próprias habilidades para tal feito.

Como se percebe, a espera pode ocorrer por dois motivos. O primeiro tipo de espera ocorre quando o sujeito quer entrar em junção com um valor. Trata-se de uma espera objetal. ${ }^{1} \mathrm{O}$ segundo tipo de espera ocorre porque o sujeito crê poder contar com a transformação de estado proporcionada pelo sujeito do fazer. Falase, então, de uma espera fiduciária. Ora, se existem dois tipos de espera, nada mais lógico do que supor a existência de dois tipos de paixão: aquelas que surgem quando o sujeito busca a junção com os seus valores e aquelas que aparecem como derivadas do contrato fiduciário entre os sujeitos.

As paixões complexas, explica Barros (1990, p. 62-63), definem-se por duas características: o maior ou menor grau de querer ser e pelo saber da possibilidade realização do desejo do sujeito da espera. O saber poder ser sobremodaliza a espera, aparecendo, então, os

\footnotetext{
${ }^{1}$ Não se pode considerar espera objetal, que faz parte uma paixão complexa, como uma paixão simples. É preciso ressaltar que, se há espera, pressupõe-se um contrato fiduciário. Portanto, trata-se de uma paixão complexa. Dessa forma, não é a junção entre sujeito e valor que faz a diferença entre paixão simples e complexa, mas sim o caminho percorrido pelo sujeito para alcançar seu valor.
} 
casos de tristeza, pesar, tormento, angústia, aflição ou, então, de alegria, felicidade, contentamento, etc.. Barros (1990, p. 63) apresenta um quadrado semiótico com essas variações de paixão determinadas pelo saber poder. Observe-se:

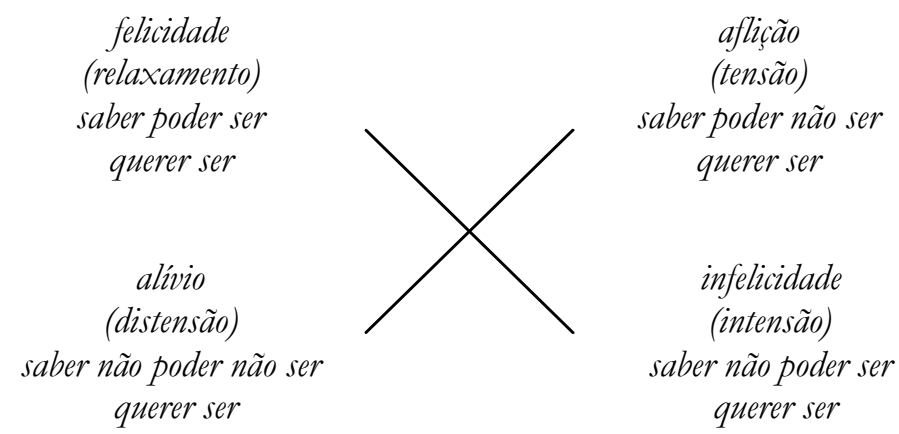

Lembra, ainda, a autora que é através do saber poder que o sujeito toma consciência da verdade ou da falsidade da sua relação com o objeto. Sendo assim, a felicidade aparece quando há o saber que a conjunção desejada épossivel. A infelicidade relaciona-se ao saber que a conjunção desejada é impossivel. Já a aflição vincula-se ao saber que a conjunção desejada é incerta, evitável, insegura. E, finalmente, o alívio está relacionado ao saber que a conjunção desejada é certa, inevitável, segura.

É preciso, ainda, considerar o grau de tensividade que está presente entre felicidade e infelicidade e entre aflição e alívio. Várias paixões lexemáticas podem ser derivadas a partir disso. Como se sabe, o grau de tensividade pode ir da tensão ao relaxamento: aflição > alívio > felicidade; ou do relaxamento à tensão: felicidade > infelicidade $>$ aflição. Barros (1990, p. 63) ${ }^{2}$ faz uma classificação, que não quer ser exaustiva, na qual lista várias paixões lexemáticas que surgem a partir dessa variação de tensividade:

\footnotetext{
${ }^{2}$ Em relação a esta classificação, a autora observa que os lexemas pesar, dor, tormento, tortura e angústia podem também ocorrer no paradigma da aflição e lembra que a diferença é, essencialmente, de tensividade.
} 


\begin{tabular}{|c|c|c|c||}
\hline FELICIDADE & INFELICIDADE & AFLIÇÃo & ALÍVIO \\
\hline felicidade & infelicidade & aflição & alívio \\
\hline contentamento & descontentamento & pena & desopressão \\
\hline satisfação & insatisfação & ansiedade & tranqüilidade \\
\hline alegria & tristeza & ânsia & desafogo \\
\hline deleite & dor & cuidado & paz \\
\hline júbilo & pesar & inquietação & \\
\hline exultação & tormento & agonia & \\
\hline prazer & tortura & & \\
\hline & angústia & & \\
\hline & frustração & & \\
\hline
\end{tabular}

Mas, com já se afirmou anteriormente, quando a espera é fiduciária, tem-se um novo grupo de paixão. Trata-se das paixões epistêmicas do crer ser, derivadas da confiança ou da decep̧ção. A propósito disso, Barros (1990, p. 64) mostra o quadrado semiótico a partir da modalidade epistêmica do crer ser:

crer ser
(relaxamento)
ex.: confiança
não crer não ser
(distensão)
ex.: segurança
despreocupação


Confiança, fé, certeza, convicção, crença, esperança, expectativa, espera, ilusão, eis algumas paixões citadas por Barros (1990) como paixões de confiança. A autora lembra que é possível perceber nelas traços de um simulacro imaginário, no qual o sujeito da espera projeta sua confiança no sujeito do fazer.

Em relação à variação de tensividade, Barros (1990, p. 65) explica que as paixões de confiança e de decepção comportam-se da seguinte maneira:

a) Percurso de aumento de tensão: relaxamento $>$ intensão $>$ tensão

\begin{tabular}{|c|c|c|}
\hline CONFIANÇA & DECEPÇÃO & INSEGURANÇA \\
\hline querer ser & querer ser & querer ser \\
crer ser & não crer ser $n a \tilde{o}$ ser \\
\hline
\end{tabular}

b) Percurso de diminuição de tensão: tensão $>$ distensão $>$ relaxamento

\begin{tabular}{|c|c|c|}
\hline INSEGURANÇA & SEGURANÇA & CONFIANÇA \\
\hline querer ser & querer ser & querer ser \\
crer não ser & não crer não ser & crer ser \\
\hline
\end{tabular}

Barros (1990) esclarece que a crise de confiança se instaura porque o contrato fiduciário estabelecido entre os dois sujeitos provouse não ser compartilhado pelo sujeito do fazer. $O$ sujeito da espera sabe que não pode mais contar com a colaboração do sujeito do fazer e que, portanto, seu desejo não vai ser alcançado. Com isso, o sujeito da espera é modalizado pelo não crer ser. É nesse momento que a espera transforma-se em decep̧̧ão. "O sujeito crédulo, confiante, passa a sujeito cético, descrente, tanto do sujeito do fazer, quanto dele próprio, sujeito de estado que não soube bem empregar sua confiança" (BARROS, 1990, p. 65).

A reiteração do estado de decepção gera outros estados passionais, como rancor, desilusão, desengano, desapontamento, 
desesperança, decepção, mágoa, desconfiança, descrença, etc. Dessa forma, a decepção (crise fiduciária) torna-se um "pivô" para o aparecimento de paixões tensas, que desestabilizam o indivíduo. Barros (1990, p. 65) salienta que a maioria desses lexemas aponta para a negação do crer-ser e para o rompimento do contrato fiduciário entre os sujeitos, e acrescenta:

Mágoa e ressentimento explicitam a duração do efeito passional e atribuem a paixão não só ao /não-fazer/ do sujeito, como também a seu fazer contrário (ofensa). Inclui-se, nesse caso, o rancor, causado, segundo o dicionário, pela ação de um sujeito prejudicial a outro.

Barros (1990) acrescenta, ainda, que a insatisfação (separação do objeto) ou decepção (crise fiduciária), quer ocorram juntas quer separadas, podem ser marcadas pela duratividade e podem também desenvolver outros efeitos passionais, como a mágoa, a resignação, a aflição e a insegurança. Estes dois últimos efeitos passionais produzem sentimento de falta. A autora (1990, p. 66) explica também que sentimento de falta "resulta do conflito entre o /querer-ser/ e o / saber poder não ser/ e o /crer não ser/".

É preciso lembrar que a insatisfação pode ser uma instância pressuposta no discurso através do sentimento passional de decepção e que o sentimento de insatisfação e de decepção cessa e cede lugar ao sentimento de falta. Se a decepção conduz a um sentimento de falta, este, por sua vez, gera um programa de liquidação da falta.

Sendo assim, é preciso salientar a função de "pivô", isto é, de termo intermediário que assume a insatisfação e a decepção entre o estado relaxado da crença, momento em que o sujeito da espera ainda cria poder contar com a ajuda do sujeito do fazer para realizar seus desejos (pseudocontrato), e a situação tensa final de falta.

Se o sentimento de falta é gerado pela insatisfação e pela decepção, infere-se que existem dois tipos de falta: a de objeto-valor, desenvolvido pelo sentimento de insatisfação, e a fiduciária ou de falta de confiança, gerado pela decepção. Por conseguinte, há dois nortes para o programa de liquidação da falta: um que tenta suprir a falta do objeto e outro que tenta lidar com a crise fiduciária. Como conseqüência imediata desse processo todo, surgem novos efeitos passionais. 
Barros (1990) salienta que a aflição e a insegurança são paixões tensas ou de falta. A felicidade e a confiança são exemplos de paixões relaxadas. Já o alivio e a segurança são classificadas como paixões distensas. E, finalmente, a insatisfação e a decepşão são exemplos de paixões intensas ou, como lembra Barros, também denominada por Zilbergerg (1982 apud BARROS, 1990), paixão de ausência. Dessa forma, no quadrado semiótico, tem-se o seguinte esquema:

paixões relaxadas
ex.: felicidade, confiança
paixões distensas
ex.: alivio, segurança

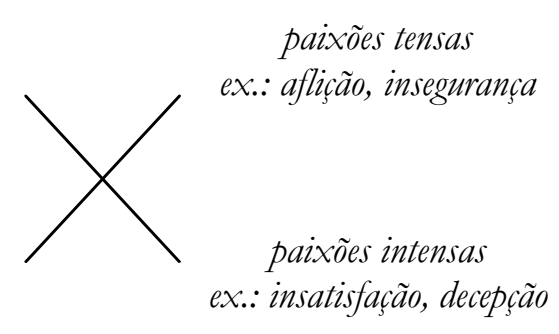

O rompimento do contrato fiduciário pode ser unilateral ou bilateral, esclarece Barros (1990). No rompimento unilateral é sempre o sujeito do fazer que corresponde à espera do sujeito de estado. Quando isso acontece, o sujeito, que tem sua espera frustrada, fragilizase e coloca-se em situação defensiva. As paixões que aparecem nesse momento são as da decepção (paixão intensa), que não conduzem à falta ou a programa de liquidação da falta. Todavia, quando o rompimento do contrato é bilateral, o sujeito é forte e ofensivo. Nesses casos, as paixões que surgem são as de falta que conduzem a programas de liquidação da falta.

A autora explica que o sujeito enfrenta o problema da falta de três modos. Primeiro, pelo prolongamento da aflição e insegurança, assumindo paixões relaxadas, como a resignação e a conformação. Segundo, o sujeito pode optar pela volta à situação de confiança e, nesse caso, constrói um novo simulacro de confiança com o sujeito do fazer. Uma terceira maneira de o sujeito trabalhar com o sentimento de falta é desenvolver um programa de reparação ou de liquidação da falta. Nesse último caso, instaura-se um sujeito do fazer, que poderá ser o mesmo sujeito que sofre a falta (sincretismo de sujeito), 
cuja missão será desenvolver programas que liquidam a falta do objetovalor ou da confiança.

Barros (1990, p. 66-67) explica que a falta de confiança produz, nas paixões tensas da falta, malevolência. Da mesma forma, quando a situação é de confiança, surge a benevolência. E esse "estado de alma" é responsável pela instauração do sujeito do fazer:

A malevolência e a benevolência interpretam, para Greimas, a hostilidade e a atração de paixões definidas pelo / querer-fazer, bem ou mal, a alguém/. O /querer-fazer/ é a modalização que dá início à competência do sujeito reparador da falta, que o instaura como tal. Dessa forma, o /querer-fazer/ que instala o sujeito reparador define-se como querer fazer mal a outro sujeito, considerado responsável pela falta.

Seguem, agora, alguns exemplos de paixões, mencionados por Barros (1990, p. 68), de benevolência e de malevolência, organizadas pelo querer fazer bem/ mal ou pelo querer não fazer mal/ bem; pelo não querer não fazer bem/mal; e pelo não querer fazer mal/ bem: ${ }^{3}$

\begin{tabular}{|c|c|}
\hline BENEVOLÊNCIA & MALEVOLÊNCIA \\
\hline & \\
\hline $\begin{array}{c}\text { 1./querer fazer bem/ } \\
\text { 2. /querer não fazer mal/ }\end{array}$ & $\begin{array}{c}\text { 1. /querer fazer mal } \\
\text { 2. / querer não fazer bem/ }\end{array}$ \\
\hline benevolência (1, 2) & malevolência (1, 2) \\
\hline benquerênça (1) & malquerença (1, 2) \\
\hline amor (1, 2) & ódio (1) \\
\hline amižade (1,2) & raiva (1) \\
\hline afeição (1,2) & rancor (1) \\
\hline
\end{tabular}

${ }^{3}$ Em nota de rodapé, a autora chama a atenção para o fato de benevolência definir-se tanto pelo querer fazer bem como pelo querer não faz̧er mal. Já os números à frente dos lexemas apontam para as possíveis combinações que o termo pode ter. 


\begin{tabular}{|c|c|}
\hline afeto $(1,2)$ & cólera (1) \\
\hline afeiçoamento $(1,2)$ & ira (1) \\
\hline simpatia (2) & indignação (1) \\
\hline \multirow[t]{9}{*}{ inclinação (2) } & aversão (2) \\
\hline & animosidade (1) \\
\hline & fúria (1) \\
\hline & execração (1) \\
\hline & inimizade $(1,2)$ \\
\hline & bostilidade $(1,2)$ \\
\hline & repulsa (2) \\
\hline & antipatia (2) \\
\hline & repugnância \\
\hline 3. / não querer não fazer bem & 3. / não querer não fazer mal/ \\
\hline apreço & desprezo \\
\hline consideração & desconsideração \\
\hline estima & desdém \\
\hline 4. / não querer fazer mal/ & 4. / não querer fazer bem/ \\
\hline indiferença & desamor \\
\hline condescendência & indiferença \\
\hline complacência & desinteresse \\
\hline
\end{tabular}

Barros (1990, p. 69) apresenta, também, um quadro das paixões de malquerença, que são aquelas que se caracterizam pelo poder fazer. Lembra antes, entretanto, que não existem paixões benevolentes do poder fazer em língua portuguesa: 


\begin{tabular}{|c|c|c|c||}
\hline $\begin{array}{c}\text { /não poder } \\
\text { fazer/ }\end{array}$ & $\begin{array}{c}\text { /poder- } \\
\text { fazer/ }\end{array}$ & $\begin{array}{c}\text { /não-poder- } \\
\text { não-fazer }\end{array}$ & $\begin{array}{c}\text { /poder não } \\
\text { fazer/ }\end{array}$ \\
\hline Desalento & ódio & fúria & resignação \\
\hline desânimo & ira & furor & paciência \\
\hline abatimento & cólera & irritação & conformação \\
\hline depressão & raiva & exacerbação & \\
\hline & rancor & & \\
\hline
\end{tabular}

A propósito deste grupo de paixões, Barros (1990) observa que o poder fažer representa a "recuperação da confiança" em si mesmo, enquanto o não poder fazer aponta para a perda total de confiança, o desalento, o desânimo. Ainda segundo a autora, este último "estado de alma", isto é, aquele marcado pelo não poder fazer, pode levar o sujeito a outros estados passionais, como a conformação e a resignação.

O sujeito que despertou a hostilidade no sujeito de estado poderá ser o destinador ou o anti-sujeito. O sujeito de estado, agora instaurado como sujeito reparador (sujeito do fazer, portanto) desenvolverá programas de revolta ou de vingança, caso o sujeito que despertou a hostilidade seja o destinador ou o anti-sujeito, respectivamente. A propósito do programa de revolta, Barros (1990, p. 70) explica:

O sujeito rejeita o destinador que faltou à palavra dada, mesmo que se trate de compromisso imaginário, pois ele se coloca na posição do destinatário que cumpriu sua parte no contrato e que espera do destinador a sanção positiva que lhe é devida, sob a forma de reconhecimento e de recompensa. Quando o destinador não o sanciona ou, além do mais, o julga negativamente, o sujeito se decepciona, se torna inseguro e aflito e se revolta.

Já em relação ao programa de vingança desenvolvido pelo sujeito que teve sua espera frustrada, Barros (1990, p. 70) ensina: 
O sujeito e o anti-sujeito, como é sabido, confrontam-se na narrativa pois estão em busca dos mesmos valores. Na vingança, o sujeito 'ofendido' assume o papel de destinador-julgador e sanciona negativamente o anti-sujeito que não cumpriu o esperado ou que exerceu um fazer contrário e prejudicial aos seus projetos. A vingança liquida a falta fiduciária, que diz respeito às relações intersubjetivas, e soluciona a crise de confiança, graças ao reconhecimento do herói e do vilão, isto é, 'ao reinstalar de novo, de forma categórica, a linguagem de verdade’.

É lógico que para o sujeito do fazer executar um programa de revolta ou de vingança, a fim de reparar o sentimento de falta, pressupõe-se que ele seja competente para isso (Barros, 1990, p. 67):

O desejo de vingança ou de revolta, causado pela violência da ofensa, representa-se, na estrutura modal, pelo /poder-fazer/ [...], que vem completar a qualificação modal do sujeito. O sujeito torna-se, então, sujeito competente para o fazer, isto é, instaurado pelo / querer-fazer/ e atualizado pelo / poder-fazer/. O / poderfazer/ é a forma de o sujeito ofendido auto-afirmar-se, graças à possibilidade de destruição do ofensor.

Como se percebe, para uma investigação e descrição das paixões complexas, não basta uma análise das modalidades que constituem o sujeito patêmico. Faz-se necessário, como explica Barros (1990), organizar os percursos em estados passionais e verificar as transformações modais que determinaram aquele estado passional. Com isso, (re)constrói-se a organização modal e passional da narrativa.

\section{Referências Bibliográficas}

BARROS, Diana Luz Pessoa de. Paixões e apaixonados: exame semiótico de alguns percursos. Cruzeiro semiótico, Porto, n. 11/12, p. 60-73, 1990.

\footnotetext{
${ }^{4}$ A última frase da citação é extraída pela autora de "De la colère. Études de sémantique lexicale", publicado em Actes Sémiotiques - Documents, Paris, III (27), p. 24.
} 
Sintaxe narrativa. In: OLIVEIRA, Ana Claudia; LANDOWSKI, Eric (Eds.). Do inteligível ao sensível: em torno da obra de Algirdas Julien Greimas. São Paulo: Educ, 1995. p. 81-99.

FONTANILLE, Jacques. Le tumulte modal: de la macro-syntaxe à la micro-syntaxe passionelle. Paris: Institut National de la Langue Française, 1986.

GREIMAS, Algirdas-Julien. De la colère. Actes sémiotiques Documents, III, 27. Paris: EHESS-GRSL, 1981.

; COURTÉS, Joseph. Sémiotique: dictionnaire raisonné de la théorie du langage. Paris: Hachette, 1986. v. 2.

Ática, 1993.

; FONTANILLE, Jacques. Semiótica das paixões. São Paulo: 